THURSDAY, MARCH I, 1877

\section{GOVERNMENT GRANTS IN AID OF SCIENCE}

THE Civil Service Estimates for this year contain three different sums proposed to be granted by the government in aid of scientific research. As the circumstances comnected with these grants do not appear to be generally well understood, it may be convenient to those engaged in the study of science to have a short explanation given to them on the subject.

The oldest and best known of these grants is that of I,00ol. which has been given to the Royal Society for the last twenty years, for the encouragement of scientific research. The distribution of this grant is regulated by a Committee of the Council and other Fellows of the Royal Society, usually denominated the "Government Grant Committee." The manner in which it is expended is given in the published Proceedings of the Royal Society every year. Last year, we observe, grants of rool. were sanctioned to Mr. J. A. Broun, for "investigating the effects due to the sun's rotation and magnetism;" to Mr. J. N. Lockyer, to enable him "to continue his spectroscopic researches ;" to Dr. Carpenter, in aid of his work on Comatula (or Antedon, as he prefers to call it) ; and to Sir W. Thomson and Prof. J. Thomson for the construction of an analysing machine suitable for performing certain calculations connected with the observation of tides. Other smaller sums were assigned to Dr. Stenhouse, Mr. G. J. Romanes, Mr. W. Crookes, and Prof. W. E. Adams, in aid of various researches in which these philosophers are respectively engaged.

Last year, as we stated on a former occasion, in consequence of the report of the Royal Commission on Science, the propriety of increasing the amount of this grant was considered by the Government. It was ultimately arranged. that instead of making any alteration in the mode of distributing the grant of $x, 000 l$, which seemed to have answered its purpose very satisfactorily, a second grant of $4,000 l$. should be made, to be admininistered in a different manner. Instead of being given by the Treasury direct to the Royal Society, the new grant, in order to carry out another recommendation of the Duke of Devonshire's Commission, to the effect that the scientific work and votes should be placed under one Minister, was placed in the Privy Council Estimates, and will be distributed directly by the Lord President, according to a scheme prepared by the "Government Grant" Committee of the Royal Society, together with the presidents of fifteen other learned societies, who, for this object, are ex officio members of this Committee.

There are now, therefore, two different grants in aid of scientific research administered by the Royal Society : that of $1,000 l$. received direct from the Treasury appropriated mainly to the providing of instruments and other assistance necessary to scientific inquiries; that of $4,000 l$. applied to the aid of scientific investigators not only by providing instruments and assistance, but by making personal allowances or grants of money to the investigators for their services. As regards the last-named fund,

VoL. $x v,-$ No. 383 on the proposed distribution of which the Government Fund Committee is now occupied, we unferstand that the applications made for it for the present financial year (18;6-77) have amounted to upwards of $14,000 \%$. To three sub-committees (Physical, Chemical, and Biological) who have been for some time past engaged in investigating these applications, is assigned the pleasing task of reducing them to more moderate dimensions, and bringing them again before the whole Committee, which meets to-day, in order that they may be submitted to the Lord President of the Council for his final approval.

When it is possible to refer to the proceedings of the Committee without any breach of confidence, we shail state at length how the great question of the endowiment of research has been aided, or the reverse, by the action of the Fund Committee. It is well known that there are many Fellows of the Royal Society whose positions as workers in science need not be too clearly defined, who view with mistrust the liberality of the Government. But we have the greatest confidence in the powerful Committee which has been formed, and believe that although it is possible mistakes may be made and endowments proposed which may perhaps have a different effect from that intended, that the proceedings of the Committee viewed as a whole will meet with the warmest approval of men of science, and that it will be aciknowledged on all hands that an important step has been taken in the direction of increasing research in our country.

A third grant for scientific purposes, which has been made for some years by the Government, is not so generally well known amongst men of science, and as a change is to be made in its administration this year, it may be as well to give a few explanations on the subject. Commencing with the year $1871-72$, as it appears from the Parliamentary return now before us, a sum of 2,000 . has been voted annually to the department of the Privy Council Office for "auxiliary scientific investigations." By reference to the same return, it will appear that in I $871-72$ and the three succeeding financial years this sum, under the recommendation of Mr. John Simon, late Medical Officer of the Privy Council and Local Government Board, was divided pretty nearly equally between Dr. Sanderson and Dr. Thudichum, portions of the grant in each case being devoted to laboratory expenses and the payment of skilled assistants. The results of this expenditure have been various reports on such subjects as "Infective Inflammation," the "Chemical Charges in the Case of Typhits," and the "Pathology of "Sheep-pox," and other scientific investigations connected with questions of public health, which have been published as appendices to Mr. Simon's reports as Medical Officer of the Privy Council and Local Government Board. Mr. Simon having resigned his office last year, and there being no longer any medical officer attached to the Privy Council Office, the vote of $2,000 \%$. has, we observe, in the Civil Service Estimates for the present year, been transferred to the Local Government Board, and will, we suppose, be administered in future by Mr. Sclater Booth, the President of the Board, under the advice of Dr. Seaton, who has succeeded Mr. Simon in his functions as principal medical officer of that department. Whether this transfer of the fund will involve any alteration in its disposal remains to be proved. 